\title{
Nerve Terminals Form But Fail to Mature When Postsynaptic Differentiation Is Blocked: In Vivo Analysis Using Mammalian Nerve-Muscle Chimeras
}

\author{
Quyen T. Nguyen, Young-Jin Son, Joshua R. Sanes, and Jeff W. Lichtman \\ Department of Anatomy and Neurobiology, Washington University School of Medicine, St. Louis, Missouri 63110
}

\begin{abstract}
To better understand the role of the postsynaptic cell in the differentiation of presynaptic terminals, we transplanted muscles that lacked postsynaptic differentiation from mutant mice into normal adult immunocompatible hosts and attached the host nerve to the grafts. Host motor axons innervated wild-type grafted muscle fibers and established normal appearing chimeric neuromuscular junctions. By repeated in vivo imaging, we found that these synapses were stably maintained. Results were different when nerves entered transplanted muscles derived from mice lacking muscle-specific receptor tyrosine kinase (MuSK) or rapsyn, muscle-specific components required for postsynaptic differentiation. Initial steps in presynaptic differentiation (e.g., formation of rudimentary arbors and vesicle clustering at terminals) occurred when wild-type neurites contacted MuSK- or
\end{abstract}

rapsyn deficient muscle fibers, either in vivo or in vitro. However, wild-type terminals contacting MuSK or rapsyn mutant muscle fibers were unable to mature, even when the chimeras were maintained for up to 7 months. Moreover, in contrast to the stability of wild-type synapses, wild-type nerve terminals in mutant muscles underwent continuous remodeling. These results suggest that postsynaptic cells supply two types of signals to motor axons: ones that initiate presynaptic differentiation and others that stabilize the immature contacts so that they can mature. Normal postsynaptic differentiation appears to be dispensable for initial stages of presynaptic differentiation but required for presynaptic maturation.

Key words: neuromuscular junction; surgical chimera; postsynaptic differentiation; presynaptic maturation; mammalian; in vivo
During development, signals pass between nerve terminals and postsynaptic cells that are necessary for synapse formation and maturation. Some nerve-derived signals that induce postsynaptic differentiation have been identified, but there is less information about retrograde signals used by postsynaptic cells to organize presynaptic differentiation. Nonetheless, multiple lines of evidence indicate that retrograde signals are crucial in regulating the development of presynaptic neurons (for review, see Fitzsimonds and Poo, 1998; Sanes and Lichtman, 1999). One way to assess how postsynaptic factors affect nerve terminal differentiation and maturation is to examine presynaptic development in transgenic animals that lack key components of the postsynaptic apparatus. At the neuromuscular junction (NMJ), several proteins, including muscle-specific receptor tyrosine kinase (MuSK) and rapsyn, have been shown to be essential for postsynaptic differentiation (Gautam et al., 1995, 1996; DeChiara et al., 1996; Glass et al., 1996, 1997; for review, see Sanes and Lichtman, 1999). MuSK is an essential part of the agrin receptor complex in the myotube membrane. Rapsyn is a cytoplasmic protein that is closely associated with acetylcholine receptors (AChRs) and is essential for the aggregation of AChRs after activation of MuSK by agrin. Accordingly, postsynaptic differentiation is profoundly disrupted in mice lacking rapsyn (Gautam et al., 1995) or MuSK (DeChiara et al., 1996).

At birth, motor axons in MuSK $-/-$ and rapsyn-/- mutant animals show severe abnormalities, including either total absence or small size of terminal arborizations and diff use growth (Gautam et al., 1995, 1996; DeChiara et al., 1996). Because MuSK and rapsyn are expressed only in the postsynaptic cell, these results imply that failure of postsynaptic differentiation leads indirectly to failure of presynaptic differentiation. However, because these mutants die at birth, it has not been possible to analyze the role of

Received March 23, 2000; revised May 10, 2000; accepted May 19, 2000.

This project was supported by grants from National Institutes of Health and the Muscular Dystrophy Association (J.W.L.) and the Bakewell NeuroImaging Fund.

Correspondence should be addressed to Dr. Jeff W. Lichtman, Department of Anatomy and Neurobiology, Washington University School of Medicine, Box 8108, 660 South Euclid, St. Louis, MO. E-mail: jeff@thalamus.wustl.edu.

Copyright (c) 2000 Society for Neuroscience $0270-6474 / 00 / 206077-10 \$ 15.00 / 0$ postsynaptic differentiation in the postnatal development of nerve terminals. We have used two methods to circumvent neonatal lethality, thereby permitting prolonged observation of synaptic differentiation. As a first step, we studied innervation of myotubes formed in vitro from rapsyn-/- or MuSK-/- myoblasts by wildtype neurons. Second, we devised a novel in vivo method for generating chimeric synapses between wild-type axons and mutant muscle fibers by transplanting whole neonatal muscles into immunocompatible wild-type hosts and allowing innervation of mutant fibers by wild-type host axons. Because the mutant muscles were in wild-type hosts, we were able to follow their maturation over several months. Both in vitro and in vivo, we found that presynaptic nerve terminals initiated differentiation in the absence of normal postsynaptic differentiation. However, even when the chimeras were maintained for up to 7 months, the motor axons failed to form stable contacts with mutant myotubes, and they did not mature to form complex arborizations. Together, these results suggest that postsynaptic cells provide two distinct types of signals that direct presynaptic development: ones to initiate presynaptic differentiation and others to stabilize presynaptic terminals so they can mature. Although postsynaptic differentiation does not seem necessary for the generation of signals to initiate presynaptic differentiation, it seems absolutely essential for the generation of signals to stabilize presynaptic nerve terminals so they can mature.

\section{MATERIALS AND METHODS}

Nerve-muscle cocultures. Methods for preparing nerve-muscle cocultures were modified from those of Lupa et al. (1990) and have been detailed by Son et al. (1999). Briefly, mononucleated cells were dissociated from hindlimbs of embryonic day 18 (E18) mouse embryos and plated on collagen-coated wells of a multichamber slide (Nunc, Naperville, IL) using DMEM containing $5 \%$ fetal calf serum, $10 \%$ horse serum, and $3 \%$ chick embryo extract. Three days after plating, $10 \mu \mathrm{M}$ cytosine arabinoside was added to suppress proliferation of undifferentiated cells. One day later, the medium was replaced by DMEM containing $5 \%$ horse serum and $3 \%$ chick embryo extract but no calf serum or cytosine arabinoside. Two days later, after myotubes had formed, neurons were dissociated from E10-E12 chick ciliary ganglia and plated on the myotubes. At this time, $1.5 \%$ chick eye extract was added to the medium. Three days later, tetramethylrhodaminelabeled $\alpha$-bungarotoxin (TRITC-BTX) was added for $1 \mathrm{hr}$ to label AChRs, and the cultures were then fixed in $1 \%$ paraformaldehyde in PBS. Fixed 
cultures were stained with mouse anti-SV2 antibody and rabbit antineurofilament (Sigma, St. Louis, MO), followed by fluorescein-conjugated goat anti-mouse IgG (Cappel, Durham, NC) and Cascade blue-conjugated goat anti-rabbit IgG (Molecular Probes, Eugene, OR).

Generation of surgical chimeric synapses. Methods for transplantation of muscles were modified from those of Wigston and Sanes (1985) (see Fig. $2 A, B)$. Adult mice were anesthetized (ketamine-xylazine, $0.15 \mathrm{ml} / 20 \mathrm{gm}$ ) and a ventral midline incision was made in the neck. The skin was reflected, and the left sternomastoid muscle was removed, leaving a long portion of the nerve to the sternomastoid intact. Neonatal [postnatal day 0 (P0)] mouse pups were anesthetized with ice, perfused transcardially with DMEM, and then immersed completely in DMEM. The left sternomastoid and cleidomastoid muscles (henceforth referred to as graft) were dissected with their bony insertions intact and immediately transferred into the neck of the host animal. The distal insertion of the graft was attached to the sternum of the host with two sutures (9-0 nylon monofilament; Ethicon, Somerville, NJ). Then, the proximal insertion of the graft was attached via the mastoid process of the temporal bone to the host animal's posterior belly of the digastric muscle with one suture. The host nerve stump to the sternomastoid muscle was attached to the mastoid process of the temporal bone of the graft with tissue glue (Nexaband; Veterinary Products Laboratories). Finally, the incision was closed with several sutures (6-0 braided silk; Ethicon) and the host animal returned to its cage for recovery.

Mice used as donors were derived from matings between heterozygous MuSK +/ - (DeChiara et al., 1996) or rapsyn $+/-$ (Gautam et al., 1995) mice. Homozygous mutants were readily identified at birth because they were nearly (rapsyn $-/-$ ) or completely $\left(\mathrm{MuSK}_{-} /-\right)$immobile, but genotypes were confirmed in each case by PCR. Littermates (wild-type, MuSK $+/-$, or rapsyn +/-) were used as controls.

To assess the possibility that host-derived myoblasts contributed to the graft, we performed two sets of control experiments. In one, we transplanted control muscles into ROSA-26 mice (The Jackson Laboratory, Bar Harbor, ME). These mice express cytoplasmic $\beta$-galactosidase in nearly all tissues, including muscles (Zambrowicz et al., 1997). This combination allowed us to seek any host-derived fibers (blue appearing) in wild-type grafts. Second, we prepared a set of grafts using RNZ mice (Pin et al., 1997) as hosts. In these mice, an MRF4 promoter drives expression of nuclear-localized $\beta$-galactosidase specifically in muscles. In these chimeras, contaminating host myonuclei would be detectable in the graft with the nuclear localization of the reaction product, providing greater sensitivity for detecting small numbers of host myoblasts incorporated into predominantly wild-type muscle fiber.

In vivo imaging. Four to 6 weeks after transplantation, the innervation of control or mutant muscle fibers by wild-type host axons was assessed in vivo using the low-light level fluorescence microscopy methods described by Lichtman et al. (1987) and van Mier and Lichtman (1994). Host mice were anesthetized as above and mechanically ventilated. A ventral midline incision was made in the neck under sterile conditions, and the submandibular gland and fat pad were retracted to expose the muscle graft. The presence of AChRs was assessed by application of TRITC-BTX $(5 \mu \mathrm{M}, 15$ min in lactated ringer), and the presence of nerve terminals was assessed by application of $10 \mu \mathrm{M}$ 4-di-2-Asp (Molecular Probes) for $1 \mathrm{~min}$ in lactated ringer. After each view, the neck incisions were sutured closed (6-0 silk; Ethicon), and the mice returned to their cage to recover. Each of the grafts was viewed two or three times, with 3-5 d between views.

Histological methods. To visualize presynaptic and postsynaptic specializations at high resolution, mice were killed with pentobarbital and transcardially perfused first with lactated Ringer's solution $\left(25^{\circ} \mathrm{C}\right)$ and then with $2 \%$ paraformaldehyde in PBS $\left(16^{\circ} \mathrm{C}\right)$. A ventral neck incision was made, the salivary glands and fat pad were retracted to expose the graft, and an additional $2 \%$ paraformaldehyde solution was applied for $30 \mathrm{~min}$. The muscle was then dissected and pinned at resting length on a Sylgardcoated dish and rinsed with PBS $\left(15 \mathrm{~min}, 25^{\circ} \mathrm{C}\right)$, immersed in $0.1 \mathrm{M}$ glycine $\left(1 \mathrm{hr}, 25^{\circ} \mathrm{C}\right)$, and then rinsed with PBS. To stain for AChRs, muscles were incubated in $5 \mu \mathrm{M}$ TRITC-BTX (in the dark, $2 \mathrm{hr}$ ). To stain the nerve terminals, muscles were then incubated in blocking solution (4\% BSA and $0.5 \%$ Triton $\mathrm{X}-100$ in PBS, $3 \mathrm{hr}$ on a continuous agitator). Incubation with primary antibodies against neurofilament (1:200; SMI312, Sternberger) or synaptophysin (1:500; A. Czernik and P. Greengard, Rockefeller University, New York, NY) was done in blocking solution (4-12 hr on a continuous agitator). Muscles were then washed in PBS and incubated with FITC-conjugated secondary antibodies dissolved in blocking solution for 1 $\mathrm{hr}$, washed, and mounted on glass slides and coverslipped with an antifade agent (Vectorshield; Vector Laboratories, Burlingame, CA).

For lacZ staining, mice were killed with pentobarbital and transcardially perfused with $2 \%$ paraformaldehyde and $0.1 \%$ glutaraldehyde in PBS, $\mathrm{pH}$ 7.4 , and then rinsed with PBS. Mouse torsos including head and neck were then stripped of skin and immersed in staining solution containing $2 \mathrm{mM}$ 4-chloro-5-bromo-3-indolyl- $\beta$-galactosidase (X-gal; dissolved in DMSO), 5 $\mathrm{mm}$ potassium ferricyanide, $5 \mathrm{~mm}$ potassium ferrocyanide, and $2 \mathrm{~mm}$ $\mathrm{MgCl}_{2}$ in PBS for $12-24 \mathrm{hr}$ at $37^{\circ} \mathrm{C}$. After staining, tissues were rinsed in PBS, and sternomastoid muscle or grafts were dissected and mounted on glass slides and coverslipped.

\section{RESULTS}

\section{Initial presynaptic differentiation in the absence of postsynaptic differentiation}

Our aim was to generate synapses between wild-type axons and neonatal muscle fibers under conditions that permit monitoring beyond the perinatal period. To this end, myoblasts from rapsyn $+/-$, rapsyn $-/-$, MuSK $+/-$, and MuSK -/- littermates were cultured. After myotubes had formed, neurons dissociated from chick ciliary ganglia were added to the culture. Ciliary neurons were used in these experiments because they are easier to isolate and culture than spinal motor neurons (Bixby and Reichardt, 1985, 1987; Role et al., 1985), extend neurites that recognize synaptic sites on skeletal muscle fibers (Covault et al., 1987), and form cholinergic synapses on striated muscles.

After $3 \mathrm{~d}$ in coculture, differentiation of nerve-muscle contacts was assayed by labeling postsynaptic AChRs, axonal neurofilaments, and synaptic vesicles. In control cultures, 26\% (122 of 471) of nerve-muscle contacts showed signs of differentiation in that the neurites formed a small array of neurofilament-poor, SV2-rich branches (Fig. 1A,B,I,J). Approximately $73 \%$ of these differentiated contacts were found overlying high-density AChRs (Fig. $1 C, K)$, whereas the remaining $27 \%$ of the contacts were on AChRpoor membranes. As discussed previously, the remaining $74 \%$ of nerve-muscle contacts lacked both presynaptic and postsynaptic differentiation (Burgess et al., 1999; Son et al., 1999). In these cases, the neurites and myotubes may not have been in close contact, or contacts may have been newly formed and not yet differentiated. A similar degree of presynaptic differentiation, as evidenced by neurofilament-poor, SV2-rich branches, was seen in cocultures with rapsyn $-/-$ and MuSK $-/-$ myotubes [26\% (73 of 281) in cultures from three animals of contacts in rapsyn-/- cocultures and $22 \%$ (66 of 302) in cultures from three animals of contacts in MuSK-/cocultures; Fig. 1E,F,M,N]. Thus, by immunohistochemical appearance, the initial steps of presynaptic differentiation appear to proceed normally, i.e., at the same rate (Fig. 1Q), in the absence of postsynaptic differentiation, because all of the differentiated nervemuscle contacts in cocultures with mutant muscle fibers occurred on AChR-poor membranes (Fig. 1G,O).

\section{Generating chimeric synapses in vivo}

To assess whether the differentiated contacts between wild-type axons on mutant muscle fibers progress to form the complex branching pattern characteristic of mature neuromuscular synapses in vivo, we needed a way to generate contacts between wild-type motor axons and neonatal muscle fibers under conditions that permit monitoring over long periods in living animals. To this end, we transplanted whole sternomastoid muscles from $\mathrm{P} 0$ donors into the neck of wild-type adult hosts (Fig. $2 A$; for details, see Materials and Methods). The host sternomastoid muscle was removed, the graft was sutured in its place, and the host's cut nerve stump was affixed to the transplant. The use of adult hosts ensured greater availability of host motor neurons to innervate transplanted muscle fibers, because axotomy in neonatal animals has been shown to cause massive motor neuron death (Kashihara et al., 1987; Pollin et al., 1991; Snider et al., 1992; Li et al., 1998). Because the rapsyn and MuSK mutants were generated from 129 ES cells and maintained in a mixed C57Bl6-129J background, F1 offspring of C57B16-129J matings were used as hosts to ensure immunocompability and thus obviate the need for immunosuppression after transplantation. The rationale is that each F1 offspring will have all the alleles of both C57B16 and 129J lines, including those responsible for tissue histocompability. Preliminary experiments confirmed that grafts were rapidly rejected by immunoincompatible hosts (data not shown). When immunocompatible hosts were used, the grafts survived for many months, and host axons grew into the graft muscle.

\section{Grafted muscles remain free of host myoblasts after transplantation}

To determine whether muscle fibers in the graft were entirely derived from the donor, control muscles were grafted into trans- 

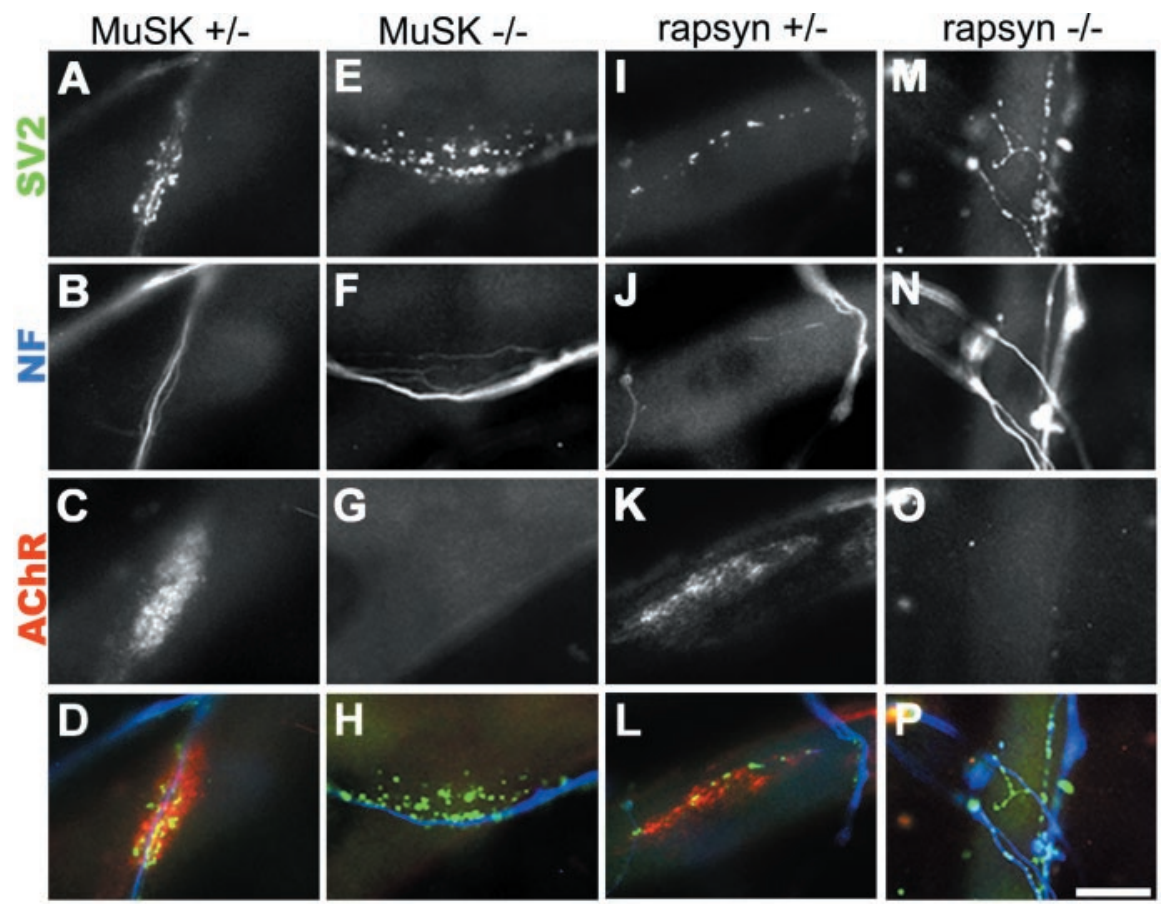

\section{Q}

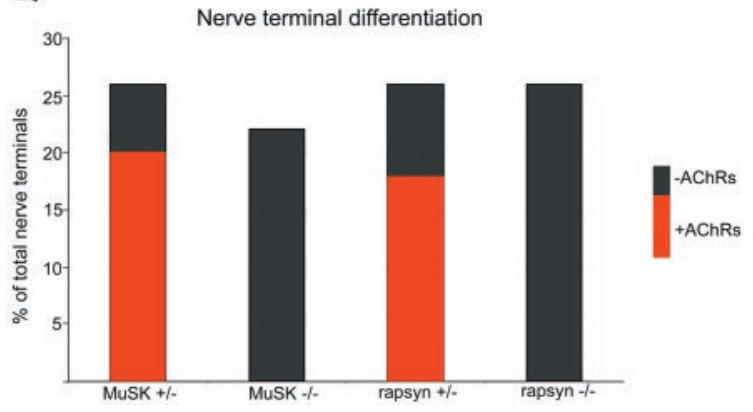

Figure 1. Nerve-muscle cocultures. $A-P$, Fluorescent photomicrographs of nerve-muscle cocultures showing terminal differentiation of neurites as evidenced by the presence of SV2 staining $(A, E, I, M)$ in neurofilament-poor $(B, F, J, N)$ areas of the nerve terminals. Twenty-six percent of nerve-muscle contacts in control cocultures $(A, B, I, J)$ showed signs of differentiation in that the neurites formed a small array of neurofilament-poor, SV2-rich branches. Approximately $73 \%$ of these differentiated contacts were found overlying high-density AChRs labeling with TRITC-BTX $(C, K)$, whereas the remaining $27 \%$ of the contacts were on AChR-poor membranes. A similar degree of presynaptic differentiation as evidenced by neurofilament-poor, SV2-rich branches was seen in cocultures with MuSK $-/-(E, F)$ and rapsyn $-/-(M$, $N)$ myotubes. All of these differentiated nerve-muscle contacts in cocultures with mutant muscle fibers occurred on AChR-poor membranes $(G, O)$. D, H, L, P, Superimposition of presynaptic and postsynaptic staining for SV2 (pseudocolored green), neurofilament (pseudocolored blue), and AchRs (peudocolored red) for control and mutant cocultures. Scale bar, $5 \mu \mathrm{m}$. $Q$, Column graph showing that the level of nerve terminal differentiation is similar in the control and mutant muscle fiber cocultures. genic hosts that expressed $\beta$-galactosidase either in the cytoplasm of all cells (ROSA-26 mice) or specifically in nuclei of muscle fibers (RNZ mice). Transplantation into the ROSA-26 hosts allowed for the detection of any host-derived cells in the graft, including Schwann cells, whereas transplantation into the RNZ hosts allowed detection of host-derived myonuclei with maximal sensitivity. Four weeks after transplantation, we saw no evidence of lacZ staining in muscle fiber cytoplasm ( $n=3$ grafts into ROSA hosts) or myonuclei ( $n=2$ grafts into RNZ hosts) of the grafts, despite the fact that adjacent host muscles were intensely lacZ-positive (Fig. 2B-F). This result indicates that muscle transplants are not populated by host muscle cell progenitors after transplantation using this protocol. In contrast, host Schwann cells did invade the grafts, because at least half the Schwann cells near the neuromuscular junctions of transplanted muscle fibers into ROSA-26 hosts were blue (data not shown). This result is consistent with the observation that neonatal terminal Schwann cells undergo apoptosis when their associated axons degenerate (Trachtenberg and Thompson, 1996), as must have occurred in these transplants causing replacement by host Schwann cells during or after reinnervation by host axons.

\section{Host axons reoccupy original synaptic sites in transplanted wild-type muscles}

At the time of transplantation, neuromuscular junctions in the control donor (P0) muscle were arranged in a band approximately midway along the length of the muscle fibers (Fig. $3 A$ ). In one set of control transplants, we determined the fate of former synaptic sites in the absence of innervation. Five days after transplantation, before the host nerve had entered the muscle, TRITC-BTX stain- ing showed that the transplanted muscle fibers maintained the original endplate band (Fig. $3 B$ ). Similar results were obtained at longer periods (10 d; Fig. $3 C$ ) in transplants kept denervated by deflecting the host nerve into adjacent host musculature. However AChR-rich plaques remained small and poorly differentiated in the aneural muscles compared with normal innervated muscles of the same age, suggesting that postsynaptic differentiation had slowed. A small subset of fibers showed multiple patches of AChR clusters along their length (data not shown), suggesting that these fibers had formed from satellite cells after the degeneration of the transplanted muscle fibers. Eventually these uninnervated grafts showed signs of extensive necrosis (i.e., fatty change). Thus, in the absence of reinnervation, the control grafts did not survive, and the postsynaptic specialization did not continue to mature.

Results were quite different in grafts to which the host nerve stump was attached. The grafted muscles were larger when examined 1-7 months after transplantation than they had been when the graft was made. The majority of muscle fibers $(>90 \%)$ in the successful grafts (10 of 13) did not appear to have degenerated and regenerated, because they did not have central nuclei. Muscle fiber necrosis and regeneration attributable to ischemia have been shown to occur within the first week after free grafting (Carlson and Gutmann, 1975), and regenerating muscle fibers have been shown to retain central nuclei for up to 6 months (Schmalbruch, 1976). The low level of ischemia-induced muscle fiber degeneration in the grafts is likely related to the small cross-sectional diameter of the neonatal mouse sternomastoid muscle used for transplantation (Wigston and Sanes, 1985). 

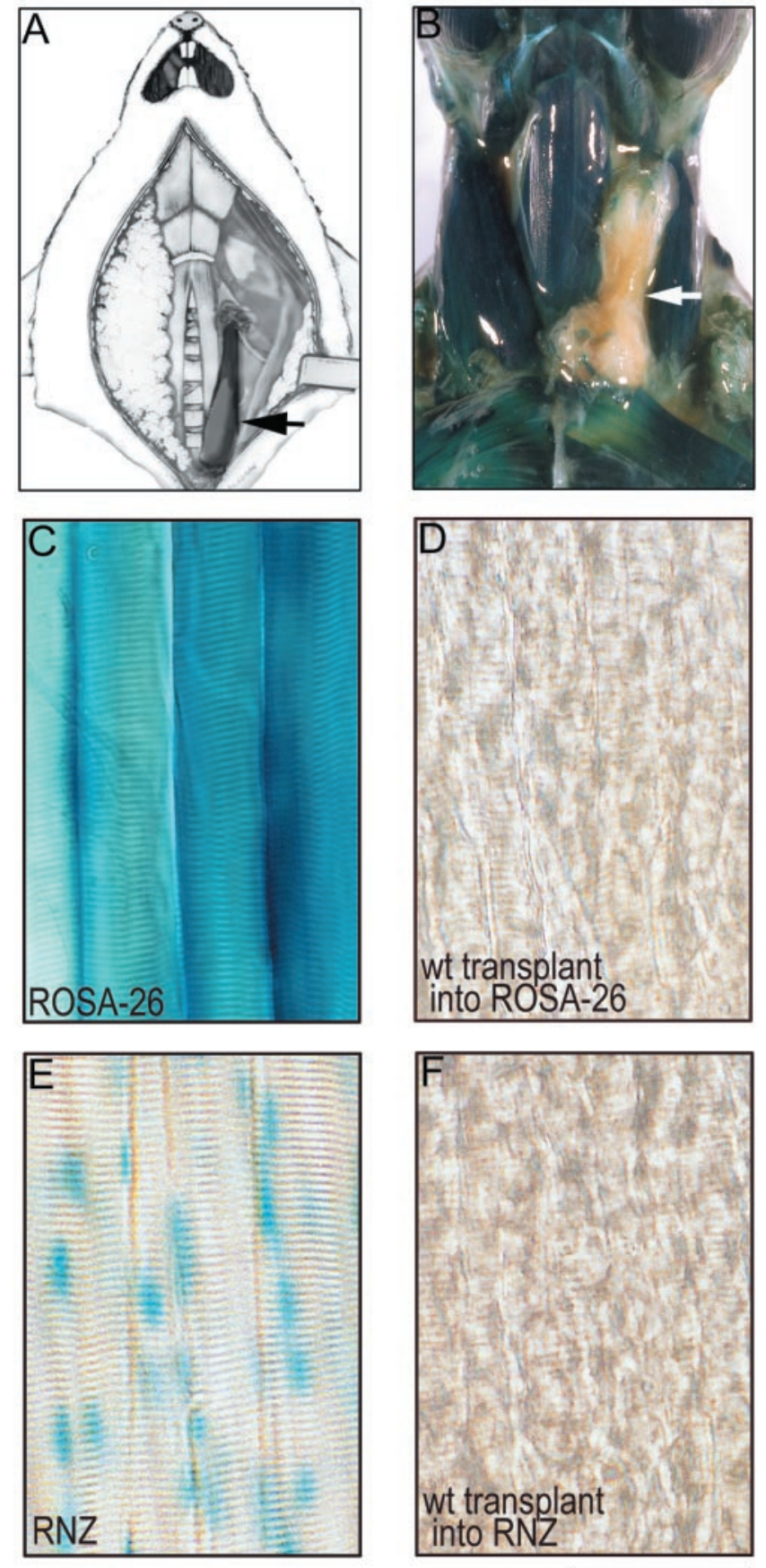

Figure 2. Transplantation method. A, Schematic of transplantation method showing a sternomastoid muscle from a P0 mouse (arrow) transplanted into the neck of an adult mouse whose own sternomastoid muscle has been removed. $B-D$, Wild-type muscle grafted into a ROSA-26 host 4 weeks after transplantation. $B$, Dissected neck of a ROSA mouse whose own left sternomastoid muscle has been replaced with a wild-type muscle graft (arrow) 1 month after transplantation. $C$, Nearly all cell types in the ROSA mice, including skeletal muscle fibers, express cytoplasmic $\beta$-galactosidase and turn blue with X-gal staining. $D$, In contrast, wild-type (wt) muscle fibers grafted into ROSA-26 hosts remain completely clear. $E$, $F$, Wild-type muscle grafted into an RNZ host. $E$, Muscle fibers in the RNZ mice express nuclear localized $\beta$-galactosidase, and thus the myonuclei in these mice turn blue with X-gal staining. $F$, In contrast, wild-type muscle fibers grafted into the RNZ mice show complete absence of blue myonuclei. These results indicate that there has been no fusion of host precursor cells with muscle fibers in the graft. Scale bar $(B-E), 100 \mu \mathrm{m}$.

All of the control grafts had an endplate band and fascicles of axons terminating near the middle of the muscle around the site of the original intramuscular nerve (Fig. $3 D$ ). In these grafts, only a few muscle fibers $(<10 \%)$ had synaptic sites at the end of the graft near the site of entry of the host nerve stump to the graft. No synapses were observed at the end of the graft that was opposite the site the nerve stump entry. A possible explanation for this pattern of innervation is that a small percentage of muscle fibers had been damaged during surgery and had degenerated; regenerating muscle fibers have been shown to be capable of forming NMJs in ectopic locations as well as at the original synaptic sites (Womble, 1986). In contrast, reinnervation of the other transplanted muscle fibers by host axons occurred by reoccupation of original synaptic sites, presumably guided by persistent cues in the graft, for example, in cells of the perineurium, or in the basal lamina or plasmalemma of muscle fibers.

\section{Synapses between host axons and wild-type muscle fibers become mature, stable, and functional}

At the time of grafting (P0), the wild-type neuromuscular junctions were simple and small (Fig. 4A). Most of these junctional sites consisted of oval concentrations of AChRs (plaques) in the muscle plasmalemma with two or more overlying unmyelinated motor axons, each of which sets down several boutons on the receptor plaque. In contrast, each NMJ in normal adult mice is composed of an AChR-rich region arranged in a complex branching pattern, and a single myelinated motor axon terminates in a branching pattern that precisely overlies the receptor branching pattern (Fig. 4B).

Four weeks after transplantation of control P0 muscles into wild-type adult hosts, each muscle fiber also showed a single AChR-rich region in a branched configuration that was overlain by a single myelinated axon with similarly branched terminal endings (Fig. $4 C$ ). Thus, control P0 muscle grafts can differentiate normalappearing postsynaptic receptor distributions, and adult motor axons have the ability to form structurally mature NMJs on these transplanted neonatal muscle fibers.

In normal adult mice, NMJs show little branch addition or retraction over days or months (Lichtman et al., 1987; BaliceGordon and Lichtman, 1990). To determine whether the junctions on transplanted muscles were also stable over time, we viewed identified NMJs stained with vital presynaptic and postsynaptic markers using low-light level fluorescent microscopy in living mice. We found that, as in normal adult muscles, the receptor distribution and nerve terminal branching pattern on individual muscle fibers remained unchanged over time (Fig. 5). Stimulation of the host muscle nerve supplying grafted wild-type muscles with a suction electrode elicited brisk and forceful contractions in all four transplants tested, indicating that the innervation was functional. Taken together, these results indicate that wild-type P0 muscle fibers survive the heterochronic transplant procedure and become functionally innervated by wild-type host motor axons. Furthermore, these chimeric synapses are stably maintained over time, similar to wild-type control NMJs.

\section{Contacts on MuSK-/- or rapsyn -/- muscle fibers show postsynaptic and presynaptic abnormalities}

We transplanted muscles from MuSK- or rapsyn-deficient neonates into wild-type adult host mice. Even 7 months after innervation of the mutant muscle fibers by wild-type axons, the postsynaptic abnormalities seen in mutant neonates (Gautam et al., 1995; DeChiara et al., 1996) persisted in both MuSK-deficient $(n=3)$ and rapsyn-deficient $(n=6)$ muscles: only three mutant muscle fibers of hundreds examined (see below) bore clustered receptors on their surfaces. This maintained absence of receptor clusters indicates that rapsyn and MuSK do not merely facilitate or accelerate postsynaptic differentiation but are absolutely essential for it to occur. These chimeric nerve-muscle contacts were therefore suitable for testing the dependence of presynaptic maturation on postsynaptic differentiation

Immunohistochemical labeling of axons and nerve terminals in rapsyn $-/-$ transplants showed that host axons often ran parallel to the length of the muscle fibers. There were occasional clusters of nerve terminal boutons on the surface of the fibers (Fig. $6 B, C$ ), but these were typically smaller than those seen in wild-type P0 mus- 

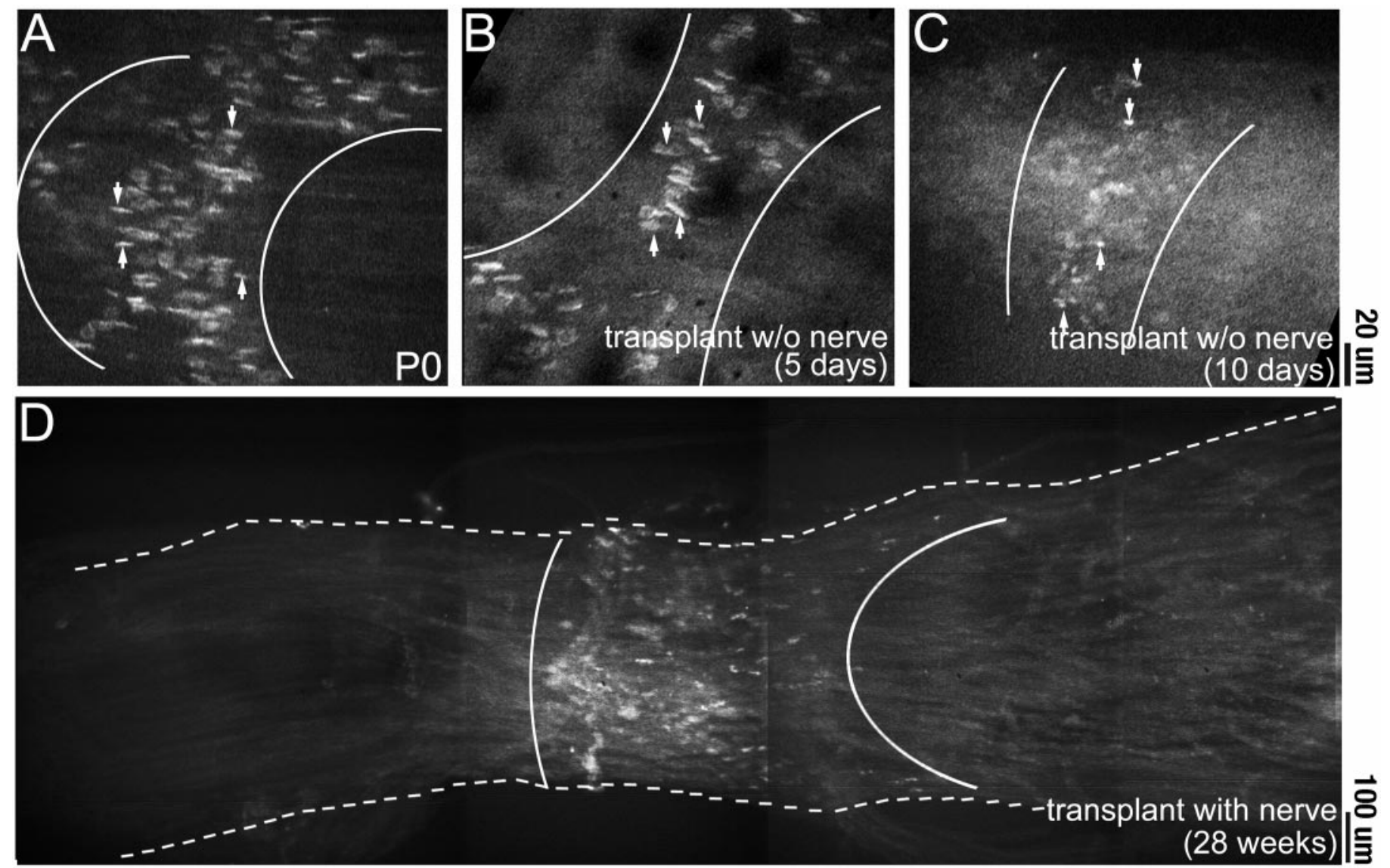

Figure 3. Stability of postsynaptic AChRs after transplantation. Photomicrographs show the AChR staining pattern with TRITC-BTX in sternomastoid muscles. A, At the time of transplantation, the NMJs (arrows) in the P0 muscle were arranged in a small cuff known as an endplate band (area between white lines) approximately midway along the length of the muscle. $B, C$, Five to $10 \mathrm{~d}$ after denervation or transplantation into a host where the host nerve was deflected from the graft, the NMJs in the muscle still maintain their tight distribution in an endplate band midway along the length of the muscle. $D$, After transplantation and attachment of the host nerve stump (28 weeks after transplantation for this particular graft), host axons innervate muscle fibers approximately midway along the length of the graft, forming an endplate band. Scale bars: $A-C, 20 \mu \mathrm{m} ; D, 100 \mu \mathrm{m}$.

cles and markedly less differentiated than nerve terminals in control transplants (compare Figs. 6B,C and $4 C 1$ ). Rather, the nerve terminals resembled immature terminals in rapsyn mutants at birth (Fig. 6A; Gautam et al., 1995). The degree of terminal maturation did not appear to change from 3 weeks to 7 months after transplantation. The presynaptic structure of host axons in the MuSKdeficient grafts after transplantation (Fig. $6 E, F$ ) was also similar to that seen in MuSK $-/-$ mutants at birth (Fig. 6D) and in the rapsyn $-/-$ chimeras described above: nearly all motor axons terminated in sparse clusters of boutons on the surface of the muscle fibers that were less differentiated than nerve terminals in control transplants (compare Figs. 6E,F and $4 C 1$ ).

Despite their overall similarities, there were two differences between the MuSK and rapsyn mutant muscle transplants. First, whereas axons grew throughout the rapsyn mutant muscles after transplantation (Fig. 7A,B), axons in the MuSK-/- grafts formed immature terminal endings that clustered around the central intramuscular nerve (Fig. 7C,D). Second, whereas no AChR clusters were found in the rapsyn-/- transplants, three muscle fibers in MuSK - / - transplants (two fibers in one transplant, one fiber in the second transplant, and none in the third transplant) bore a remarkably normal-appearing, high-density AChRs cluster with a complex branching pattern (data not shown). This observation is especially dramatic and raises the possibility of a MuSKindependent pathway for postsynaptic differentiation (also see Sugiyama et al., 1997; Gautam et al., 1999). We cannot, however, rule out the possibility that it results from the invasion of the graft by a few host satellite cells, which fused with mutant muscle fibers and supplied them with MuSK. No AChR clusters were ever seen in rapsyn $-/-$ transplants, but rapsyn is needed at a 1:1 stoichiometry with AChRs, whereas a small number of MuSK molecules may be sufficient to induce postsynaptic differentiation. Further studies will be needed to evaluate these alternatives.

\section{Nerve terminal contacts on MuSK-/- or rapsyn-/- muscle fibers are unstable}

In that presynaptic differentiation is initiated at points of axonal contact with rapsyn $-/-$ or MuSK $-/-$ myotubes, the defects observed are likely to reflect defects in the maturation process per se. To gain insight into the ways in which maturation fails, we visualized identified synaptic sites multiple times in living animals.

In contrast to muscles from normal mice and control transplants, there are no postsynaptic markers that can be vitally labeled in the mutant muscle fibers. Thus, we had to depend on other landmarks such as the position of the blood vessels to relocate individual muscle fibers. In doing the multiple-view experiments in the mutant transplants, we took extreme care to image nerve terminals only when the blood vessel landmarks themselves are in the same orientation as the initial views. We found that whereas in control transplants nerve terminals and the postsynaptic AChR sites could be relocated with little difficulty over 4-5 d (see Fig. 5), nerve terminals on MuSK-/--transplanted (Fig. 8) and rapsyn-/-transplanted (data not shown) muscles changed greatly during this interval. In MuSK transplants, although there were contact sites that remained identifiable over a $4 \mathrm{~d}$ period $(n=7$ sites in two animals), there were also many contact sites that were present on the first view but were no longer present at the second view $4 \mathrm{~d}$ later ( $n=8$ sites in two animals). In addition, new sites of contact that were not present at the first view were seen at the second view $(n=$ 4 sites in two animals). Thus, over a $4 \mathrm{~d}$ period, $\sim 30 \%$ of contact 

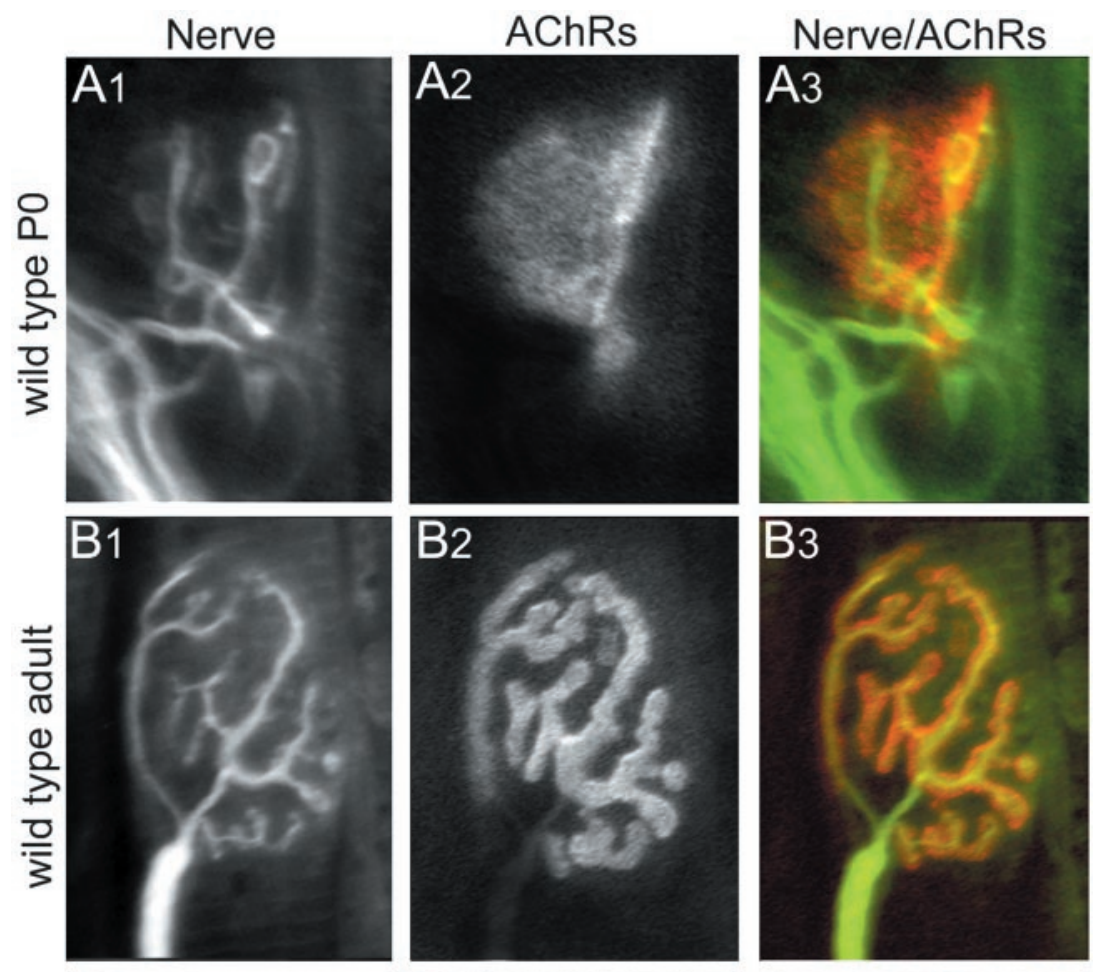

Figure 4. Comparison of NMJs from wild-type P0, adult, and transplanted muscle fibers. $A$, At $\mathrm{P} 0$, nerve terminals and synaptophysin) have small bouton-like endings overlying a plaque-like area of high $\mathrm{AChR}$ density $(A 2$, labeled with TRITC-BTX; $A 3$, overlay of nerve terminal pattern on AChR pattern). $B$, By 4-6 weeks postnatally in mice, each muscle fiber receives innervation from a single myelinated axon whose arbors show extensive branching (B1). The postsynaptic AChR cluster underlying the presynaptic nerve terminals also shows breaking apart of the original plaque to form a high, branched structure (B2). The preters correspond exactly in their branching pattern (B3). C, Four weeks to 10 months after transplantation, wild-type muscle fibers are also innervated by a single axon. The overall size of the NMJs in transplanted muscle fibers is smaller compared with normal adult NMJs, probably because of the fact that the neonatal graft was placed in a full sized adult host, and thus the muscle fibers themselves do not lengthen and are consequently smaller than their agematched nontransplanted counterparts. The presynaptic (C1) and postsynaptic (C2) components of the NMJs in wild-type transplanted muscle fibers exactly oppose each other $(C 3)$ and show the branching morphology similar to that seen in normal nontransplanted NMJs. The difference in presynaptic arbor width between $B 1$ and $C 1$ reflects variability in antibody staining for synaptophysin and does not reflect differences in presynaptic structure between wild-type adult and wild-type transplants. Scale bar: $A, C, 5$
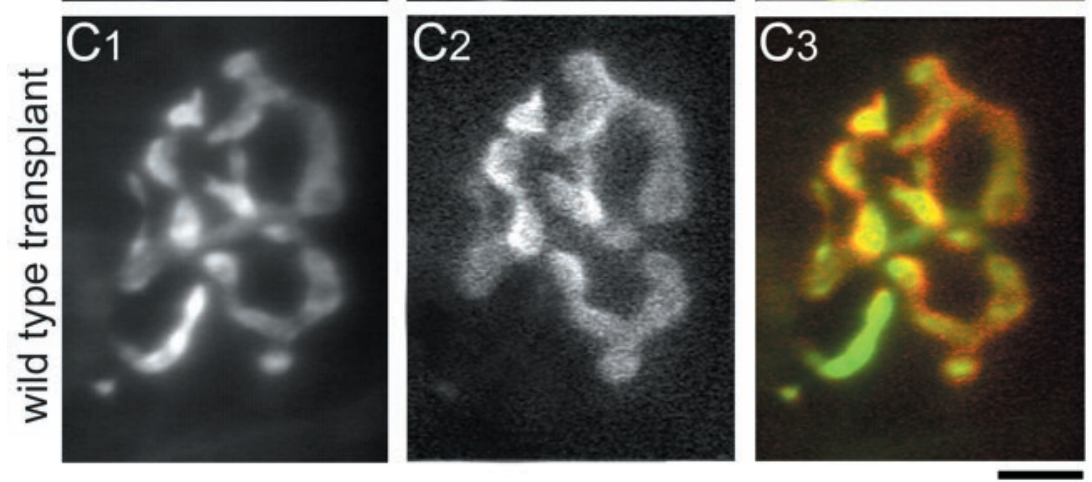
$\mu \mathrm{m} ; B, 12.5 \mu \mathrm{m}$.

sites in MuSK transplants were maintained, whereas the remaining $70 \%$ appeared to have either retracted or grown additional terminal endings.

Host axons innervating rapsyn-deficient muscle fibers were at least as labile as those innervating $\mathrm{MuSK}-/-$ muscles. Indeed, contact sites present on the first view were never reidentified on the second views 2-4 d later, even though the sites where the nerve terminals were previously observed were unambiguously reidentified using blood vessels as landmarks $(n=30$ nerve terminals followed over $2 \mathrm{~d}$ and 14 nerve terminals followed over $4 \mathrm{~d}$ in two animals). Thus, $100 \%$ of synaptic sites in rapsyn transplants appeared to undergo remodeling over intervals of probably $<48 \mathrm{hr}$. This contrasts with control grafts described above in which 73 of 75 NMJs (in three animals) identified at the first view were reidentified 3-5 d later.

\section{DISCUSSION}

MuSK and rapsyn are required for postsynaptic differentiation at the NMJ. When mice lacking rapsyn or MuSK were generated, it was found that presynaptic as well as postsynaptic differentiation were severely compromised (Gautam et al., 1995; DeChiara et al., 1996). In MuSK -/- mice, it was reported that no presynaptic differentiation occurred at all; motor axons failed to branch or to concentrate synaptic vesicles, and they remained similar to preterminal axons (DeChiara et al., 1996). Using high-power confocal microscopy, we did find some evidence of presynaptic specialization in MuSK $-/-$ mice at birth (Fig. $6 D$ ), although these terminals
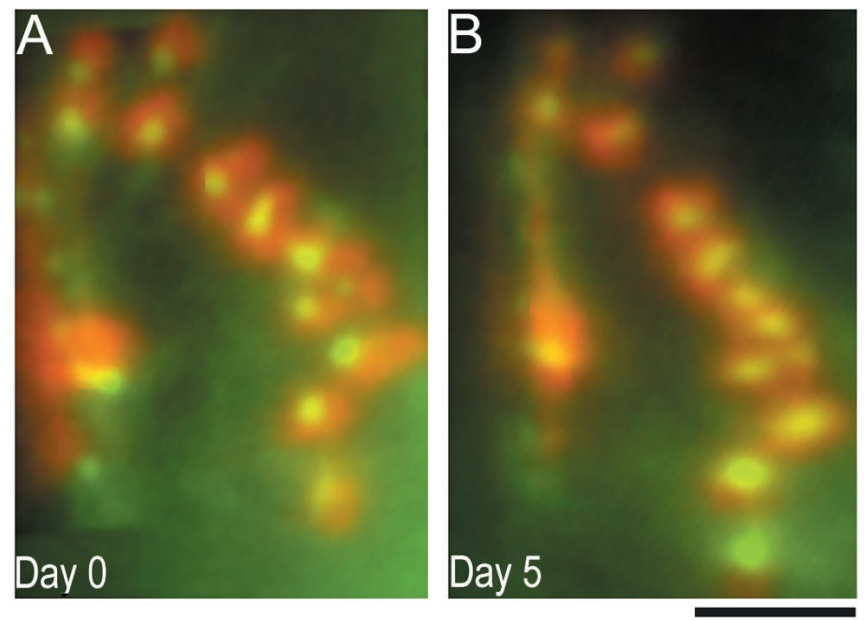

Figure 5. Innervation of control muscles by host axons is stable over time. Stability of heterochronic NMJs on transplanted wild-type muscle fibers viewed in vivo over $5 \mathrm{~d}$ are shown. $A$, On day 0 , host presynaptic nerve terminals (labeled with the vital mitochondrial dye 4-di-2-Asp, green) innervating grafted muscle fibers overlie postsynaptic AChR clusters (labeled with TRITC-BTX, red). Presynaptic nerve terminals overlie areas of AChR clusters with precise correspondence (the red and green pseudocolors of the AChRs and nerve terminals combine to give yellow). $B$, Five days later, the presynaptic and postsynaptic components of the NMJ still retained their close association and are unchanged from day 0 . Scale bar, $25 \mu \mathrm{m}$. 

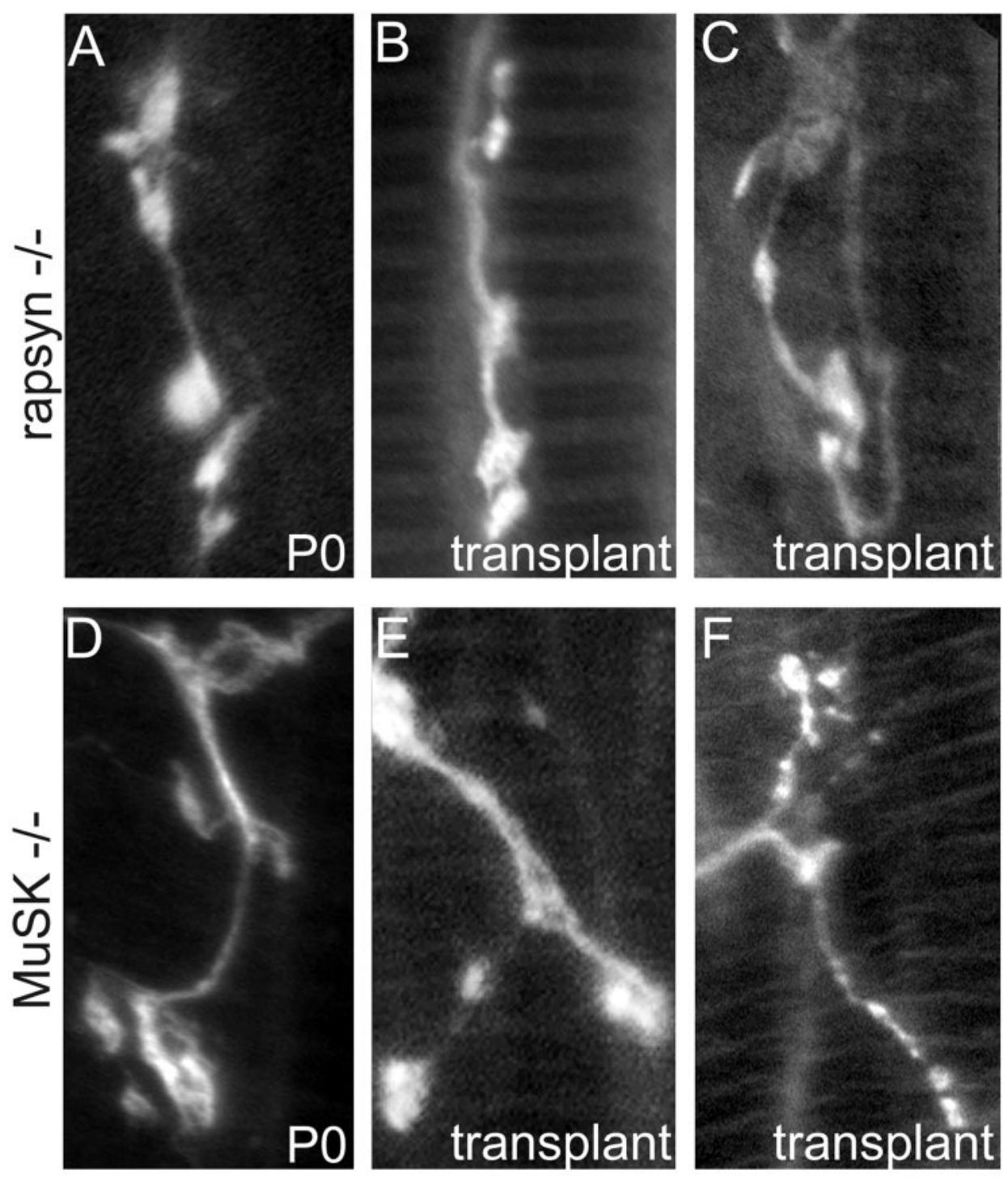

Figure 6. Innervation of rapsyn-/- and MuSK $-1-$ muscle fibers by wild-type host axons. $A$, High-power photomicrograph showing the small bouton-like nerve terminal endings immunolabeled with antibodies against neurofilament and synaptophysin in rapsyn $-/-$ mutants at P0. B, C, Several months (2.5 and 3 months for these grafts) after transplantation, normal host axons still only terminate in bouton-like endings without further maturating into the complex branching pattern of normal mature nerve terminals or nerve terminals innervating muscle fibers in the wild-type transplants (compare $B, C$ with Fig. $4 B 1, C 1$ ). $D$, High-power photomicrograph showing the small bouton-like nerve terminal endings in MuSK-/- mutants at P0. E, F, Normal host axons innervating MuSK $-/-$ muscle fibers still terminated in bouton-like endings after 4 months (compare $E$, $F$ with Fig. $4 B 1, C 1$ ). Scale bar: $A-E, 5 \mu \mathrm{m} ; F, 10 \mu \mathrm{m}$. were much smaller and simpler than those of wild-type mice at birth. In rapsyn-/- mice, some presynaptic and postsynaptic differentiation did occur, but both presynaptically and postsynaptically, the defects were still devastating (Gautam et al., 1995). Because rapsyn and MuSK are both expressed only in the postsynaptic cell, it was hypothesized that the presynaptic defects resulted indirectly from lack of retrograde signals that are normally elaborated as part of the program of postsynaptic differentiation. Here, we have used muscles from MuSK $-/-$ and rapsyn $-/-$ mice to test this hypothesis. To this end, we used dissociated cultures and a novel transplantation paradigm to examine genotypically chimeric synapses over a protracted period. Surprisingly, initial steps of presynaptic differentiation did occur in the absence of postsynaptic differentiation: both in vitro and in vivo, wild-type motor axons generated varicosities, synaptic vesicle clusters, and rudimentary arbors on mutant muscle fibers. Thus, although the myotube organizes the initial steps in presynaptic differentiation, as demonstrated by the invariable apposition of nerve terminals to the myotube surface, these steps do not require postsynaptic differentiation. In contrast, even when the chimeric synapses were maintained for up to 7 months in vivo, they failed to mature. Furthermore, such endings appeared to undergo continuous remodeling. Thus, postsynaptic differentiation is required to stabilize nervemuscle contacts, and stability, in turn, may permit maturation of presynaptic nerve terminals. Together, our results suggest that postsynaptic cells provide two distinct types of signals to their synaptic inputs: some that organize early events in presynaptic differentiation and others that lead to stabilization and maturation of the nerve terminal. Postsynaptic differentiation seems to be dispensable for initial presynaptic differentiation but is required for presynaptic maturation.

There are several advantages to studying synaptic development in surgical chimeras. First, because the mutant muscle is transplanted into a wild-type host, the viability of the animal is not compromised by lethal mutations. Thus, synapses can be viewed over long intervals, and developmental delay can be distinguished from developmental blockade. Indeed, the initial failure to detect presynaptic differentiation in $\mathrm{MuSK}-/-$ mice (DeChiara et al., 1996) is presumably a consequence of their neonatal lethality. Second, in situations in which the molecules of interest are present in multiple tissues, concerns about indirect effects on synapse development arising from the deletion of these molecules from nonmuscle tissues is circumvented. Third, because the motoneurons arise and extend axons in a normal environment, it is possible to isolate the retrograde effects that impinge directly on synapses.

The first aim of our transplant experiments was to evaluate the ability of adult motoneurons to innervate neonatal muscle fibers. Neonatal and adult motoneurons show different dependence on their targets (Kashihara et al., 1987; Pollin et al., 1991; Snider et al., 1992), and neonatal and adult muscles show different responses to denervation (Blondet et al., 1986, 1989; Rodrigues Ade and Schmalbruch, 1995). Such differences, or the mismatch in age 

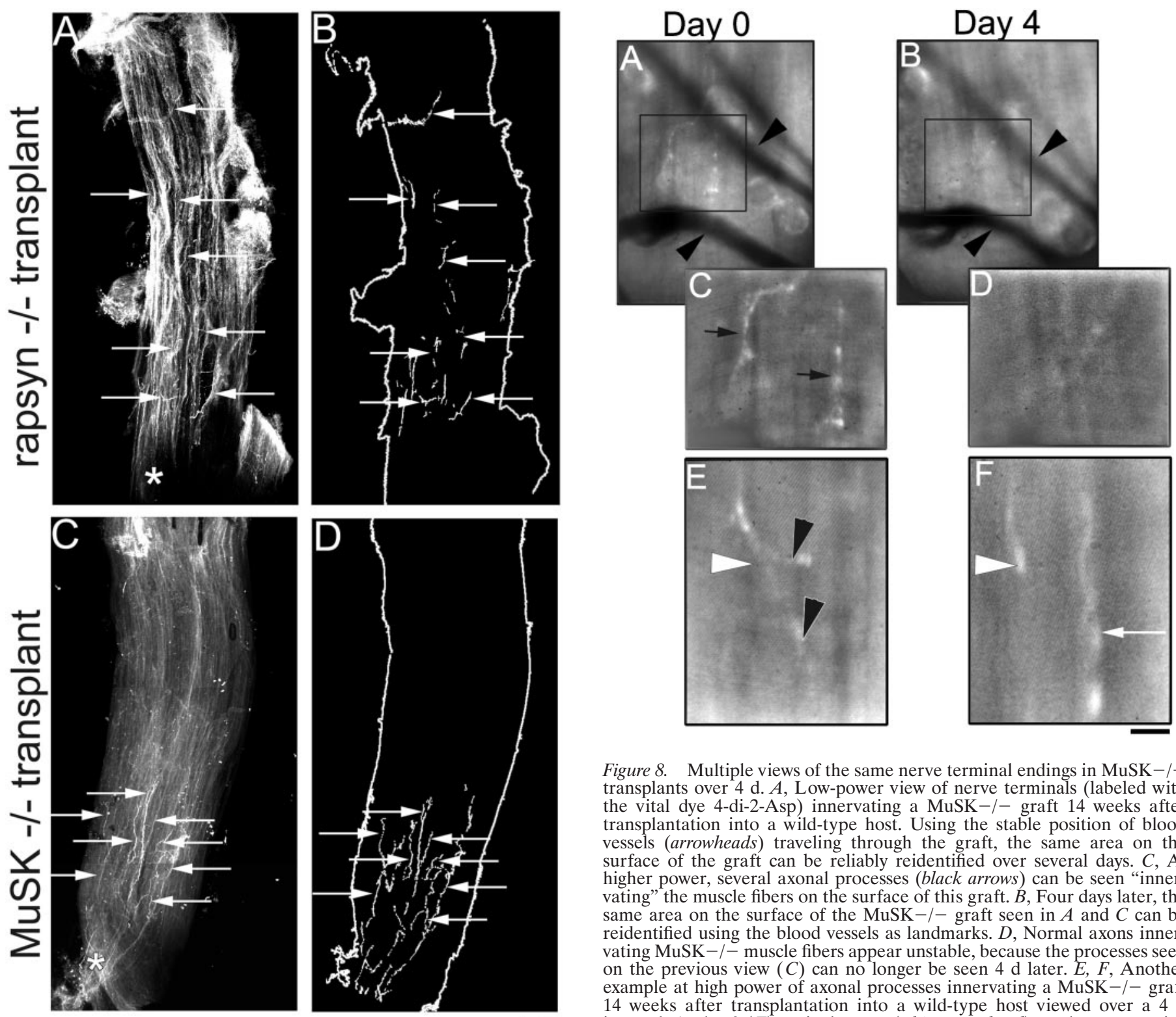

Figure 8. Multiple views of the same nerve terminal endings in MuSK-/transplants over $4 \mathrm{~d}$. $A$, Low-power view of nerve terminals (labeled with the vital dye 4-di-2-Asp) innervating a MuSK-/- graft 14 weeks after transplantation into a wild-type host. Using the stable position of blood vessels (arrowheads) traveling through the graft, the same area on the surface of the graft can be reliably reidentified over several days. $C$, At higher power, several axonal processes (black arrows) can be seen "innervating" the muscle fibers on the surface of this graft. $B$, Four days later, the same area on the surface of the MuSK-/- graft seen in $A$ and $C$ can be reidentified using the blood vessels as landmarks. $D$, Normal axons innervating MuSK $-/-$ muscle fibers appear unstable, because the processes seen on the previous view $(C)$ can no longer be seen $4 \mathrm{~d}$ later. $E, F$, Another example at high power of axonal processes innervating a MuSK-/- graft 14 weeks after transplantation into a wild-type host viewed over a $4 \mathrm{~d}$ interval. At day $0(E)$, a single axon (white arrowhead) can be seen to give off two terminal branches (black arrowhead). Four days later $(F)$, the two terminals branches previously seen appeared to have retracted, and a new axonal process (white arrow) appeared to have grown into the area. Scale bar: $A, B, 20 \mu \mathrm{m} ; C, D, 10 \mu \mathrm{m} ; E, F, 5 \mu \mathrm{m}$.

Distribution of host axons in rapsyn- - and MuSK - - $A$, Low-power photomicrograph showing an example of the innervation pattern of a rapsyn $-/-$ muscle after transplantation into a wild-type host (11 weeks after transplantation). Normal host axons innervating rapsyn -/muscles terminate far away from the entry point of the intramuscular nerve (asterisk). B, Schematic of rapsyn-/- graft in $A$, showing that nerve terminal endings (arrows) can be found throughout the length of the graft. (Note: the fragmented appearance of the nerve terminals is attributable to the fact that innervating axons weave between the muscle fibers of the graft and thus disappear from the plane of focus.) $C$, Low-power photomicrograph showing an example of a MuSK $-/-$ muscle after transplantation into a wild-type host ( 7 months after transplantation). In contrast to the diffuse innervation pattern of muscles in MuSK $-/-$ mutants at P0, after transplantation, wild-type axons innervating $\mathrm{MuSK}-/-$ muscles terminate closely to the entry point of the intramuscular nerve (asterisk). D, Schematic of the MuSK $-1-$ graft shown in $C$, showing that nerve terminal endings (arrows) are found in a tight cluster near the middle of the graft along its length. Scale bar, $200 \mu \mathrm{m}$.

between the presynaptic and postsynaptic partners, might have affected synapse formation and maintenance. We found, however, that adult wild-type motor neurons have the ability to form functional and stable synaptic contacts with neonatal wild-type muscle fibers. For the majority of transplanted neonatal muscle fibers, reinnervation by host axons appeared to have occurred by the reoccupation of original synaptic sites, as occurs after reinnervation of adult muscles. Moreover, the synaptic contact between adult wild-type axons and transplanted neonatal muscle fibers is stable over time, similar to that of control NMJs. The ability of adult motor axons to form mature synapses on an initially immature muscle has interesting clinical implications for free grafts used in reconstructive surgery.

The second aim of these transplantation experiments was to evaluate postsynaptic development of mutant muscle fibers in an otherwise normal environment. Postsynaptic differentiation of the $\mathrm{NMJ}$ includes a number of steps that ordinarily occur in postnatal life, after mutants lacking agrin, MuSK, or rapsyn die. These steps, including the $\gamma$ to $\epsilon$ switch in AChR subunits (Mishina et al., 1986; $\mathrm{Gu}$ and Hall, 1988; Missias et al., 1996), the change in channel kinetics (Schuetze and Role, 1987; Villaroel and Sakmann, 1996), the phosphorylation of AChRs (Qu et al., 1990) and the increase in their half-life in the postsynaptic membrane (for review, see Salpeter and Loring, 1985), the appearance of $\alpha 7 \mathrm{~A}-$ and B-integrin isoforms (Martin et al., 1996) and laminin $\beta 2$ (Patton et al., 1997) in the synaptic basal lamina, the generation of postsynaptic folds (Desaki and Uehara, 1987; Marques and Lichtman, 2000), and the elimination of multiple innervation (Redfern, 1970; for review, see 
Jansen and Fladby, 1990), may be mediated by signaling pathways that are independent of agrin, MuSK, or rapsyn. Thus, given enough time, it seemed possible that in mutant muscles, postsynaptic differentiation would cross over to dependence on molecular cascades different from those associated with agrin, MuSK, or rapsyn. However, we found that with rare exceptions $(\ll 1 \%$ of fibers), no normal NMJs formed on MuSK-/- and rapsyn-/myotubes even up to seven months after transplantation. The apparent failure of postsynaptic differentiation to take place even though the muscle fibers were alive for several months confirms the conclusion (Gautam et al., 1995; DeChiara et al., 1996) that rapsyn and MuSK do not merely accelerate or facilitate postsynaptic differentiation in the wild-type animal, but that, rather, both of these molecules are absolutely necessary for postsynaptic differentiation to take place.

The third and principal aim of our study was to assess presynaptic differentiation in the absence of postsynaptic differentiation. We found that wild-type adult axons innervating transplanted rapsyn- or MuSK-deficient muscle fibers either in vivo or in vitro did proceed through initial steps of presynaptic differentiation, forming some varicosities, vesicle clusters, and rudimentary arbors. In general, these terminals were similar to those of neonatal axons in the mutant animals at P0. The terminals failed to mature, however, even when they were maintained for months. The persistence of the presynaptic defect in rapsyn- or MuSK-deficient muscle fibers after transplantation suggests that in the absence of these postsynaptic molecules, presynaptic nerve terminals are fundamentally incapable of maturing, rather than merely delayed in their maturation. Because MuSK and rapsyn are drastically different in their structure and function [rapsyn is a cytosolic membrane-associated protein that is present in a 1:1 ratio with AChRs (Froehner et al., 1981; LaRochelle and Froehner, 1986; Noakes et al., 1993), whereas MuSK is a transmembrane receptor tyrosine kinase (Valenzuela et al., 1995)], it is likely that the similarity in the presynaptic defects of axons innervating muscle fibers lacking either of these proteins results from failure of a common retrograde signal whose formation, localization, or release requires postsynaptic differentiation.

One clue to the mechanism underlying the defect in presynaptic maturation in the absence of postsynaptic differentiation is the observation that host axons innervating rapsyn- or MuSK-deficient muscle fibers are in constant flux with continuous growth and retraction of terminal endings. Although wild-type axons appeared capable of some degree of presynaptic differentiation on either rapsyn- or MuSK-deficient muscle fibers, such endings underwent continuous remodeling after transplantation. These results suggest that postsynaptic cells provide two types of signals to innervating axons: ones to initiate presynaptic differentiation and ones to stabilize immature nerve terminals so they can mature. As demonstrated by the presence of presynaptic differentiation seen in the dissociated cultures and after transplantation, postsynaptic differentiation does not appear to be required for the initiation of nerve terminal differentiation. In contrast, the lability of immature presynaptic nerve terminals innervating mutant muscle fibers suggests that postsynaptic differentiation is required for the stabilization of immature nerve terminals so they can mature.

The nature of the stabilizing retrograde signals is not yet known. Studies at Caenorhabditis elegans and Drosophila NMJs suggest that target cell activity influences synaptic structure and function. For example, decreasing muscle activity in $C$. elegans induces sprouting of motor neurons (Zhao and Nonet, 2000), and changes in postsynaptic receptor density in Drosophila muscle induce corresponding changes in presynaptic neurotransmitter release (Petersen et al., 1997; Davis and Goodman, 1998). However, physical contact with target cells in the absence of any activity can also influence presynaptic development, because the preferential association of synaptic vesicle-containing neurites with myotubes was still observed when the myotubes were previously fixed with paraformaldehyde (Lupa and Hall, 1989; Lupa et al., 1990). In the present situation, the retrograde signals for nerve terminal stabilization may be either positive (e.g., anchoring molecules) or negative (e.g., failure to downregulate signals that promote continued growth). The requirement for postsynaptic differentiation in the stabilization of synaptic connections implies that postsynaptic dedifferentiation could lead to presynaptic instability. Indeed, one view of the mechanism of naturally occurring synapse elimination is that it is instigated by changes in the postsynaptic cell that include the same characteristic seen in the mutant muscles studied here: the absence of a high density of postsynaptic AChRs at sites of synapse destabilization (for review, see Lichtman and Colman, 2000). It is therefore possible that downregulation of MuSK signaling or rapsyn expression within a muscle fiber could elicit synapse loss.

\section{REFERENCES}

Balice-Gordon RJ, Lichtman JW (1990) In vivo visualization of the growth of pre- and postsynaptic elements of neuromuscular junctions in the mouse. J Neurosci 10:894-908.

Bixby JL, Reichardt LF (1985) The expression and localization of synaptic vesicle antigens at neuromuscular junctions in vitro. $\mathrm{J}$ Neurosci 11:3070-3080

Bixby JL, Reichardt LF (1987) Effects of antibodies to neural cell adhesion molecule (N-CAM) on the differentiation of neuromuscular contacts between ciliary ganglion neurons and myotubes in vitro. Dev Biol 119:363-372.

Blondet B, Rieger F, Gautron J, Pincon-Raymond M (1986) Difference in the ability of neonatal and adult denervated muscle to accumulate acetylcholinesterase at the old sites of innervation. Dev Biol 117:13-23.

Blondet B, Rieger F, Verdiere-Sahugue M (1989) Activity-independent modulation of acetylcholine receptor levels in rat skeletal muscle following neonatal denervation. Neurosci Lett 102:273-278.

Burgess RW, Nguyen QT, Son YJ, Lichtman JW, Sanes JR (1999) Alternatively spliced isoforms of nerve- and msucle-derived agrin: their role at the neuromuscular junction. Neuron 23:33-44.

Carlson BM, Gutmann E (1975) Regeneration in free grafts of normal and denervated muscles in the rat: morphology and histochemistry. Anat Rec 183:46-62.

Covault J, Cunningham JM, Sanes JR (1987) Neurite outgrowth on cryostat sections of innervated and denervated skeletal muscle. J Cell Biol 105:2479-2488.

Davis GW, Goodman CS (1998) Synapse-specific control of synaptic efficacy at the terminals of a single neuron. Nature 392:82-86.

DeChiara TM, Bowen DC, Valenzuela DM, Simmons MV, Poueymirou WT, Thomas S, Kinetz E, Compton DL, Rojas E, Park JS, Smith C, DiStefano PS, Glass DJ, Burden SJ, Yancopoulos GD (1996) The receptor tyrosine kinase $\mathrm{MuSK}$ is required for neuromuscular junction formation in vivo. Cell 85:501-512.

Desaki J, Uehara Y (1987) Formation and maturation of subneural apparatuses at neuromuscular junctions in postnatal rats: a scanning and transmission electron miscroscopical study. Dev Biol 119:390-401.

Fitzsimonds RM, Poo MM (1998) Retrograde signaling in the development and modification of synapses. Physiol Rev 78:143-170.

Froehner SC, Gulbrandsen V, Hyman C, Jeng AY, Neubig RR, Cohen JB (1981) Immunofluorescence localization at the mammalian neuromuscular junction of the Mr 43,000 protein of Torpedo postsynaptic membranes. Proc Natl Acad Sci USA 78:5230-5234.

Gautam M, Noakes PG, Mudd J, Nichol M, Chu GC Sanes JR, Merlie JP (1995) Failure of postsynaptic specialization to develop at neuromuscular junctions of rapsyn-deficient mice. Nature 377:232-236.

Gautam M, Noakes PG, Moscoso L, Rupp F, Scheller RH, Merlie JP, Sanes JR (1996) Defective neuromuscular synaptogenesis in agrin-deficient mutant mice. Cell 85:525-535.

Gautam M, DeChiara TM, Glass DJ, Yancopoulos GD, Sanes JR (1999) Distinct phenotypes of mutant mice lacking agrin, MuSK, or rapsyn. Brain Res Dev Brain Res 114:171-178.

Glass DJ, Bowen DC, Stitt TN, Radziejewski C, Bruno J, Ryan TE, Gies DR, Shah S, Mattsson K, Burden SJ, DiStefano PS, Valenzuela DM, DeChiara TM, Yancopoulos GD (1996) Agrin acts via a MuSK receptor complex. Cell 85:513-523.

Glass DJ, Apel ED, Shah S, Bowen DC, DeChiara TM, Stitt TN, Sanes JR, Yancopoulos GD (1997) Kinase domain of the muscle-specific receptor tyrosine kinase (MuSK) is sufficient for phosphorylation but not clustering of acetylcholine receptors: required role for the MuSK ectodomain? Proc Natl Acad Sci USA 94:8848-8853.

Gu Y, Hall ZW (1988) Immunological evidence for a change in subunits of the acetylcholine receptor in developing and denervated rat muscle. Neuron 1:117-125.

Jansen JK, Fladby T (1990) The perinatal reorganization of the innervation of skeletal muscle in mammals. Prog Neurobiol 34:39-90.

Kashihara YM, Kuno M, Miyata Y (1987) Cell death of axotomized motoneurons in neonatal rats, and pits prevention by peripheral reinnervation. J Physiol (Lond) 386:135-148.

LaRochelle WJ, Froehner SC (1986) Determination of the tissue distributions and relative concentrations of the postsynaptic 43-kDa protein and the acetylcholine receptor in Torpedo. J Biol Chem 261:5270-5274. 
Li L, Houenou LJ, Wu W, Lei M, Prevette DM, Oppenheim RW (1998) Characterization of spinal motoneuron degeneration following different types of peripheral nerve injury in neonatal and adult mice. J Comp Neurol 396:158-168.

Lichtman JW, Colman H (2000) Synapse elimination and indelible memory. Neuron 25:269-278.

Lichtman JW, Magrassi L, Purves D (1987) Visualization of neuromuscular junctions over periods of several months in living mice. J Neurosci 7:1215-1222.

Lupa MT, Hall ZW (1989) Progressive restriction of synaptic vesicle protein to the nerve terminal during development of the neuromuscular junction. J Neurosci 9:3937-3945.

Lupa MT, Gordon H, Hall ZW (1990) A specific effect of muscle cells on the distribution of presynaptic proteins in neuritis and its absence in a C2 muscle cell variant. Dev Biol 142:31-43.

Marques MJ, Conchello JA, Lichtman JW (2000) From plaque to pretzel: fold formation and acetylcholine receptor loss at the developing neuromuscular junction. J Neurosci 20:3663-3675.

Martin PT, Kaufman SJ, Kramer RH, Sanes JR (1996) Synaptic integrins in developing, adult and mutant muscle: selective association of $\alpha 1, \alpha 7 \mathrm{~A}$, and $\alpha 7 \mathrm{~B}$ integrins with the neuromuscular junction. Dev Biol 174:743-754.

Mishina M, Takai T, Imoto K, Noda M, Takahashi T, Numa S, Methfessel C, Sakmann B (1986) Molecular distinction between fetal and adult forms of muscle acetylcholine receptor. Nature 321:406-411.

Missias AC, Chu GC, Klocke BJ, Sanes JR, Merlie JP (1996) Maturation of the acetylcholine receptor in skeletal muscle: regulation of the AChR gamma-to-epsilon switch. Dev Biol 179:223-238.

Noakes PG, Phillips WD, Hanley TA, Sanes JR, Merlie JP (1993) 43K protein and acetylcholine receptors colocalize during the initial stages of neuromuscular synapse formation in vivo. Dev Biol 155:275-280.

Patton BL, Miner JH, Chiu AY, Sanes JR (1997) Localization, regulation and function of laminins in the neuromuscular system of developing, adult and mutant mice. J Cell Biol 139:1507-1521.

Petersen SA, Fetter RD, Noordermeer JN, Goodman CS, DiAntonio A (1997) Genetic analysis of glutamate receptors in Drosophila reveals a retrograde signal regulating presynaptic transmitter release. Neuron 19:237-248.

Pin CL, Ludolph DC, Cooper ST, Klocke BJ, Merlie JP, Konieczny SF (1997) Distal regulatory elements control MRF4 gene expression in early and late myogenic cell populations. Dev Dyn 208:299-312.

Pollin MM, McHanwell S, Slater CR (1991) The effect of age on motor neurone death following axotomy in the mouse. Development 112:83-89.

Qu ZC, Moritz E, Huganir RL (1990) Regulation of tyrosine phosphorylation of the nicotinic acetylcholine receptor at the rat neuromuscular junction. Neuron 4:367-378.

Redfern PA (1970) Neuromuscular transmission in newborn rats. J Physiol (Lond) 209:701-709.

Rodrigues Ade C, Schmalbruch H (1995) Satellite cells and myonuclei in long-term denervated rat muscles. Anat Rec 243:430-437.
Role LW, Matossian VR, O'Brien RJ, Fischbach GD (1985) On the mechanism of acetylcholine receptor accumulation at newly formed synapses on chick myotubes. J Neurosci 5:2197-2204.

Salpeter MM, Loring RH (1985) Nicotinic acetylcholine receptors in vertebrate muscle: properties, distribution and neural control. Prog Neurobiol 25:297-325.

Sanes JR, Lichtman JW (1999) Development of the vertebrate neuromuscular junction. Annu Rev Neurosci 22:389-442.

Schuetze SM, Role LW (1987) Developmental regulation of nicotinic acetylcholine receptors. Annu Rev Neurosci 10:403-457.

Schmalbruch H (1976) The morphology of regeneration of skeletal muscles in the rat. Tissue Cell 8:673-692.

Snider WD, Elliott JL, Yan Q (1992) Axotomy-induced neuronal death during development. J Neurobiol 23:1231-1246.

Son YJ, Patton BL, Sanes JR (1999) Induction of presynaptic differentiation in cultured neurons by extracellular matrix components. Eur J Neurosci 11:3457-3467.

Sugiyama JE, Glass DJ, Yancopoulos GD, Hall ZW (1997) Laminininduced acetylcholine receptor clustering: an alternative pathway. J Cell Biol 139:181-191.

Trachtenberg JT, Thompson WJ (1996) Schwann cell apoptosis at developing neuromuscular junctions is regulated by glial growth factor. Nature 379:174-177.

Valenzuela DM, Stitt TN, DiStefano PS, Rojas E, Mattsson K, Compton DL, Nunez L, Park JS, Stark JL, Gies DR (1995) Receptor tyrosine kinase specific for the skeletal muscle lineage: expression in embryonic muscle, at the neuromuscular junction, and after injury. Neuron 15:573-584.

van Mier P, Lichtman JW (1994) Regenerating muscle fibers induce directional sprouting from nearby nerve terminals: studies in living mice. J Neurosci 14:5672-5686.

Villaroel A, Sakmann B (1996) Calcium permeability increase of endplate channels in rat muscle during postnatal development. J Physiol (Lond) 496:331-338.

Wigston DJ, Sanes JR (1985) Selective reinnervation of intercostal muscles transplanted from different segmental levels to a common site. J Neurosci 5:1208-1221.

Womble MD (1986) The clustering of acetylcholine receptors and formation of neuromuscular junctions in regenerating mammalian muscle grafts. Am J Anat 176:191-205.

Zambrowicz BP, Imamoto A, Fiering S, Herzenberg LA, Kerr WG, Soriano P (1997) Disruption of overlapping transcripts in the ROSA beta geo 26 gene trap strain leads to widespread expression of betagalactosidase in mouse embryos and hematopoietic cells. Proc Natl Acad Sci USA 94:3789-3794.

Zhao H, Nonet ML (2000) A retrograde signal is involved in activitydependent remodeling at a $C$. elegans neuromuscular junction. Development 127:1253-1266. 